\title{
A Polêmica como História de longa duração: ciceronianos e anticiceronianos do século XVII
}

Eduardo Sinkevisque

\section{Resumo:}

Demonstra-se que a questão dos estilos ciceroniano/anticiceroniano concernidos à oratória e à escrita da História, nos séculos XVI/XVII, pode ser definida como uma Polêmica de longa duração, ou longuíssima, em virtude de atualizar, singularmente, um tipo de debate travado desde a Antiguidade romana (século I da Era Cristã), passando pelo Humanismo, até a Modernidade. Após definir Polêmica como gênero, definir ciceronianismo/anticiceronianismo, discutem-se exemplos de usos do debate estilístico e de poder das representações discursivas em alguns dos historiadores, retores e preceptistas mais significativos do século XVII ibérico-italiano, como Cabrera de Córdoba (1619), Manuel Severim de Faria (1624), Frei Vicente do Salvador (1630), Famiano Strada (1632) e Agostino Mascardi (1636). Nesse sentido, a Polêmica seiscentista do estilo agudo em História repõe a querela antiga dos estilos.

Palavras-chave: Polêmica; arte histórica; aticismo; asianismo; estilo

\begin{abstract}
:
This paper discusses examples of the stylistic debate uses and power of discursive representations in some of historians, retors and in the most significant treatises of the Iberian and Italian seventeenth century, as Cabrera de Córdoba (1619), Manuel Severim de Faria (1624), Frei Vicente do Salvador (1630), Famiano Strada (1632) and Agostino Mascardi (1636). Therefore, the seventeenth-century Controversy acute style in History restores the old Controversy of styles.
\end{abstract}

Keywords: Controversy; historical art; Atticism; Asianism; style 
Antes de começar, propriamente, meu texto, esclareço que uso o conceito de longa duração retirado de Braudel, porém apenas no sentido de duração secular de eventos, em oposição a eventos ocorrências. Ignoro seu sentido econômico-social, o qual muitos historiadores questionam (BRAUDEL, 1974, p. 44). O gênero Polêmica tem muitos nomes como debate, querela, contenda, controvérsia, peleja, discórdia. Muitas são as faces das contendas, entretanto podem ser definidas como diatribe (dialéxis), ou seja, como crítica severa e mordaz, tipo de escrita ou discurso agressivo e injurioso - que tem relação com o diálogo por meio de seu caráter argumentativo, mas que com ele não se confunde, pois nem toda argumentação é uma diatribe. Diatribe é uma palavra grega que teria seus usos mais remotos na Filosofia - discurso preambular de auctoritates estoicas e cínicas, como as Diatribai de Epicteto (108 a.C.), recolhidas por Flávio Arriano. Bion de Borístenes (séc. IV a.C.) atribui o sentido de "agressividade" e de "ofensa" ao gênero. Seus usos na sátira, tanto grega (comédia propriamente) quanto romana, têm seus exemplos modelares em Varrão e Cícero ${ }^{1}$. Qualquer que seja o termo adotado para Polêmica, todos carregam sentidos bélicos, como dicionariza Rafael Bluteau. Ao consultar o Vocabulário..., serão encontrados verbetes que se ocupam dos conceitos mencionados acima. Com a exceção de diatribe, termo ausente no Vocabulário, Bluteau normatiza debate como contenda, disputa, altercação, controvérsia. Polêmica o letrado diz ser guerrear, chegando a conceituar o termo como uma "arte" que "vale o mesmo que a arquitetura militar". Estende o significado de Polêmica: "na disposição da batalha, e forma de pelejar" (BLUTEAU, 1712, vols. 2, 6).

As controvérsias e seus aspectos dialéticos e retóricos foram estudadas por Jorge Sallum, que explica o gênero e seu funcionamento por meio das divisões argumentativas e lógicas, por exemplo, de Sêneca, o Velho, das Controversiae em relação à prescrição ou preceituação das staseis, de Hermágoras (SALUM, 2010).

\footnotetext{
${ }^{1}$ Cf. E-Dicionário de Termos Literários de Carlos Ceia. Disponível em <http://www.edtl.com.pt/>. Acessado em 27/05/2015.
} 
Klaus Berger dá como características da diatribe (dialéxis) ser o ouvinte apostrofado no singular e adjetivado, cuja opinião é presumida. Diz ter sua "origem" na conferência escolar, pois a rigor a diatribe significa "aula de escola superior". Segundo Berger, o diálogo pertence ao epidítico, onde há relato, e a diatribe pressupõe identidade entre autor e a quem dirige a conversa, prestando-se bem à carta (BERGER, 1998, p. 104-105). Bakhtin \& Volochinov (2004) diferenciam Polêmica "aberta" de Polêmica "velada", como fenômenos discursivos configuradores de posições sociais e ideológicas, cuja perspectiva é a do diálogo, da interlocução. A Polêmica é "velada" quando "a palavra do outro permanece fora dos limites do discurso do autor, mas este discurso a leva em conta e a ela se refere". A Polêmica é "aberta" quando o discurso refutado aparece explicitado na fala de quem o profere ou de modo indireto (BAKHTIN, 2008, p. 223).

Penso que Polêmica é sempre gênero misto, misturado. Discurso do monstro, porque demonstrativo. Se penso assim, penso com Aristóteles, da Retórica, lembrando que, como epidítica (ou demonstrativa), a Polêmica vitupera ou elogia, rebaixa ou levanta detratores ou partidários de argumentos, ideias, conceitos, pensamentos. Mas penso também no deliberativo, pois se aconselha algo em uma Polêmica, nem que seja a agir, a posicionar-se. E penso também no judicial, pois ajuíza-se contra ou a favor de uma causa em uma Polêmica. Eis aí, então, o monstro, o gênero impuro, misturado, de que se trata.

A história dos debates sobre estilo em prosa segundo Cícero, seus apoiadores e detratores, por exemplo, instaura-se como Polêmica desde sempre. No "Humanismo", ganha estatuto central no tocante à imitação. Envolvendo ataques e defesas, vaidades afetadas por humores sanguíneos e juízos beligerantes, letrados disputam a hegemonia das representações retóricas e políticas também por meio desse debate. No século I da Era Cristã, a querela romana do ciceronianismo é embate entre os estilos ático/asiático, ciceroniano/anticiceroniano, nobre ou simples, dos genera dicendi grande/humile/vehemens para imitação oratória e, por homologia, para a imitação em prosa histórica. Os principais retores envolvidos são Quintiliano (Cartas a Pompeu) e Sêneca (Controvérsias; Cartas a Lucílio).

Posicionando-se contrariamente ao anônimo ad Herenium e a Cícero dos diálogos sobre oratória, do Orador e do Brutus, Quintiliano e Sêneca propõem vários 
modelos imitativos. Selecionam e combinam essa variedade, não separando imitatio de emulatio. Cícero pensa essas categorias sem propor a ruptura delas com o costume. Para Quintiliano e Sêneca, pela variação e combinação de modelos, as categorias têm mobilidade, singularidade e multiplicidade.

Cícero, no De Oratore define o estilo do gênero histórico como "abundante y sostenido, fluído y apacible, sin la aspereza judicial ni el aguijón de las contiendas forenses" (CÍCERO, s/d, II, p. 96). Angélica Chiappetta propõe, com relação ao estilo no Orador ciceroniano, haver

três genera dicendi. Um, o dos grandiloqui que usam amplamente a gravidade das sentenças e a majestade das palavras, que são veementes, variados, copiosos, graves, que estão preparados para comover e alterar os ânimos. No extremo oposto, há o genus dos oradores tênues, que são agudos, que ensinam todas as coisas e fazem-nas mais brilhantes mas não mais amplificadas, oradores sutis e limati, ou seja, burilados, aperfeiçoados. Entre os dois gêneros há um intermediário, o dos oradores temperati, que não têm nem o raio fulminante dos primeiros nem a agudeza dos últimos [Or. 20-21] (CHIAPPETA, 2000/2001, p. 345).

A discussão estilística se atém à tripartição dos gêneros e a seus decoros. $\mathrm{O}$ aticismo romano é uma espécie de reabilitação do estilo humilde oratório dos antigos cônsules. Há diferenças entre os aticismos de Cícero e os de Sêneca. O primeiro gera, por meio da clareza e de uma ponderação ornamental, efeitos de "elegância" e de "naturalidade" do genus humile da interlocução oral, com base na neglegentia diligens do decoro das cartas e dos diálogos. O segundo, estoico, caracteriza-se pela brevidade e obscuridade do estilo epigramático, "cortado", "denso", às vezes, "solto" ou coupé. O genus medium, asiático, é para Cícero o estilo suave e ornado do gênero demonstrativo encomiástico que visa a ensinar e deleitar, mas sem excessos. O genus vehemens, um dos cernes das censuras contra Cícero dos séculos XV/XVI/XVII, é amplo, copioso, grave, ornado. Caracteriza-se como um dos principais objetos das censuras, pois é, por definição, o estilo oratório que Cícero e seus partidários propõem, ao contrário do lacônico, de Sêneca e de Tácito, reciclado no século XVII por meio das apropriações de Lipsio, principalmente. Grande parte dos jesuítas associam as leituras de Sêneca e de Tácito às teses de Maquiavel. Desde o século XVI, em Portugal, há reações de teólogos às propostas de $O$ Príncipe, de Maquiavel. 
Os teólogos opõem-se a Maquiavel, que se afasta do modelo sacro de virtude cristã. Jerônimo Osório, o principal teórico ibérico contrário a Maquiavel, afirma a excelência do Cristianismo frente às teses políticas do florentino, reconhecendo a vigência de uma ordem moral que a religião de Jesus pressupõe e impõe. As teses de Maquiavel foram identificadas ao luteranismo, calvinismo, reformismo, que se insurgiam contra a ordem tradicional da Escolástica católica de que Roma era símbolo. Segundo Albuquerque, Tácito "prestava-se às mil maravilhas para a afirmação e atuação (...) do utilitarismo em política. O Tibério de Tácito era o irmão mais velho do Príncipe de Maquiavel" (ALBUQUERQUE, 1974, pp. 103-104).

O debate "humanista" entre partidários e contrários de Cícero tem por objeto os modos de imitar, não a própria imitação. O que se debate é se Cícero deve ou não ser modelo exclusivo da imitação. Os principais agentes são: Angelo Ambrogni (14541494), Paolo Cortesi (1465-1510), Erasmo (1469-1536), Justo Lipsio (1547-1606). Ambrogni, na Lição Inaugural (...) sobre Quintiliano, em Florença, propõe reorganizar e amplificar de modo singular a definição ciceroniana de eloquência dominada pelo gênero epidítico, imitando um extrato do De Oratore (I, 8, 29). Mediado pelo conceito de urbanidade, move-se civilizatoriamente, tendo a retórica como máquina. Polemiza com Paolo Cortesi por meio de cartas. Ambrogni pensa haver leitores que preferem cartas longas, outros, cartas breves, outros que desejam maior argumentação. Há leitores que exigem estilo transparente, outros obscuro; negligente, ou diligente; simétrico ou assimétrico; ático ou asiático; a alegria ou a gravidade; as figuras ou a falta delas. Para Cortesi, Cícero é de todos o melhor modelo. Ambrogni nomeia os partidários de Cícero de "macacos" ou "papagaios". Contudo, a partir de 1528, com os Diálogos Ciceronianos de Erasmo, a querela é reeditada, ganhando dimensões continentais que se prolongam pelos séculos XVI/XVII. Seus contornos, agora, muito variados, redundam em abundância de edições, comentários e antologias. Erasmo, ao se opor ao culto italiano e/ou italianizante de letrados que elegem Cícero (cartas familiares) mestre da escrita, prolonga e enriquece a posição de Ambrogni, entre outras posições contrárias a Cícero. Um dos postulados é variar não só pelo prazer de variar, mas para adaptar harmoniosamente o estilo ao destinatário. Outro argumento erasmiano para rechaçar seus opositores é o de que o próprio Cícero não tinha modelo único para imitação oratória. Para Erasmo, os partidários de Cícero fazem do orador um cristão antes do 
tempo, entendendo que seu culto é um modo supersticioso e fanático de transformá-los em pagãos. Com Lipsio, o embate ganha certo estoicismo, principalmente colhido em Sêneca.

Esse estoicismo define-se por meio da expressão semina virtus. Lipsio a emprega, conjugando a paz terrestre com a celeste, levando em consideração modelos dos grandes antigos como meio de organizar a cidade (a urbanidade, civilidade urbanitas, civilitas) terrestre e de fazer uma reflexão e uma aproximação menos indigna da cidade celeste. (MOUCHEL, 1999, p. 460). Lipsio adere à doutrina retórica e teológica de Santo Agostinho, aderindo também às virtudes romanas rejeitadas pelos partidários de Cícero. As apropriações lipsianas de Sêneca implicam prescrever a "arte de ser bom", cujas bases estoicas propõem uma ética das virtudes morais mediadas pela razão e pelo controle de paixões como a ira, a inveja e a cobiça entre outras, para que, no discurso e na vida, sejam coincidentes as virtudes da esfera privada com as da esfera pública em termos de "bem comum", estilo oratório e atividade política. Ou seja, pela concórdia, pela responsabilidade de cada membro em relação aos demais, a noção de "bem comum" implica a consciência dos interesses coletivos, cujo fim unifica-se no todo. O estilo cortado (dividido), sentencioso (pontudo) ou pontiagudo que Lipisio recupera e com o qual faz o optimus stylus é derivado da escrita da história de Tácito entendida como hortus et seminarium praeceptorum. Com o laconismo de Lipsio impõem-se a noção de arguta dictio. É acutus ou argutus o estilo com o qual se exprime um pensamento com aparência bruta, densa, opaca, mas que exige do destinatário que este dissolva essa contração e retome em si mesmo o efeito agudo provocado pelo locutor (MOUCHEL, 1999, pp. 470-471).

Particularizo a discussão com debate sobre estilo do gênero histórico seiscentista. Entendo o Dell'Arte Historica, de Agostino Mascardi, inserido na Polêmica do estilo agudo, dos estilos em Polêmica entre partidários e contrários de Cícero aplicados, principalmente, à oratória sacra, ao gênero epistolar e ao gênero histórico. Em 1636, Agostino Mascardi, "Príncipe", ou principal, da Academia dos Humorados de Roma, publica o Dell' Arte Historica em um círculo de letrados cuja dedicação à prática de um tipo de "filosofia moral" e à pratica de uma poesia sublime, em conformidade com as doutrinas da Igreja Católica pós-tridentina, levava-os a lutar contra a heresia, celebrando o florescimento das artes liberais e da filosofia moral, na proteção de uma 
Igreja consolidada. Esforçavam-se por praticar uma eloquência didática, eficaz o suficiente para corresponder ao programa teológico-político-retórico de Urbano VIII, rival de Giambattista Marino. A rivalidade estabelecia-se de academia para academia ("humorados" versus "adormecidos"), de cidade-Estado para cidade-Estado (Gênova versus Roma).

A Academia dos Humorados era pública e universitária. A dos Adormecidos era privada e citadina, de formato republicano. Em discussão estava o estilo, em particular o estilo agudo, mas principalmente questões de poder. Mascardi pensava regular o engenho e a agudeza por meio do juízo, enquanto Peregrini propunha um "estilo novo", em que o engenho e a agudeza se autonomizassem do juízo. Marino foi responsável por uma eloquência sacra, de aliança teológico-retórica, cujos modelos são menos os Padres que os sofistas, seus mestres e rivais. A "segunda sofística", da qual Marino se apropria, caracteriza-se pelo triunfo do gênero epidítico privado da finalidade cívica, mas tendendo ao deleite. Fumaroli propõe Marino como asianista ferrenho, capaz de levar esse estilo às últimas consequências (FUMAROLI, 1994, p. 215). Marino polemiza também com Angelo Grillo nas discussões sobre usos da agudeza no gênero epistolar e conversacional, como estuda Graziosi (2000). Nos séculos XVI/XVII, há particularizações também católicas da Polêmica em Portugal, na Espanha e na França. O chamado ciceronianismo/anticiceronianismo "humanista" dos séculos XV/XVI remonta à querela romana antiga do estilo ático x asiático. A discussão seiscentista do estilo agudo concernida à oratória, à epistolografia e à prosa histórica pode ser pensada como apropriações e particularizações de rivalidades estilísticas e de poderes, que reciclam as disputas romanas pelo estilo; depois, as chamadas querelas "renascentistas", cujas interpretações católicas, nos séculos em questão, são desdobramentos específicos e singulares. Entendo estilo agudo aquele dotado de agudeza, isto é, engenhoso, maravilhoso, feito por meio de metáforas distantes, singulares, peregrinas. Estilo que afeta a recepção ao ponto de ela pensar que são seus os argumentos que ouviu ou leu como verdadeiros. Por ciceronianismo, penso o estilo suave e ornado, harmônico, redondo, ramado, copioso; asiático. O anticiceronianismo se define por meio de um estilo lacônico colhido em Sêneca e em Tácito, reciclados nos séculos XVI/XVII por meio das apropriações de Lipsio; é o ático do debate. Ciceronianos quinhentistas e seiscentistas doutrinam o estilo como não ordinário, sem perda de nexos, nem da 
correspondência entre as partes do todo. Estilo proporcional, simétrico, simples, cujo uso da sentença deve ser sem pompa, com modéstia, contrário à obscuridade. Estilo agudo, mas dotado de agudeza não indiscriminada, regulada segundo prescrições de Mascardi, Peregrini e Vieira, por exemplo. Ciceronianos aconselham ter em vista a claridade e o ornamento ao escrever história. A frase deve ser "chã" e oblíqua, não reta. O estilo histórico deve ser puro, sem uso de epítetos supérfluos, de modo que a história seja simples e graciosa, elegante, harmônica, verdadeira e com juízo.

Mascardi aconselha para o discurso do gênero histórico um tipo de elocução que se afaste do ordinário, mas sem perda dos nexos, nem das correspondências entre as partes em relação ao todo. $\mathrm{O}$ estilo recomendado para o gênero histórico é aquele que comove breve e eficazmente, pois vigoroso e arrebatador. No Delle acutezze (...), Matteo Peregrini faz uma doutrina sobre a "indiscreta afetação da agudeza" dos que, segundo ele, são os "enfarinhados das letras", letrados adeptos do estilo "moderno". Estes, segundo Peregrini, não têm perfeição de juízo porque, com a presunção de saber tudo, costumam ter o juízo muito corrompido quando aplicam a agudeza indiscriminadamente (PEREGRINI, 1639). Mesma discussão de Mascardi no Dell'Arte Historica e de Vieira, no Sermão da Sexagésima. No cap. XII, Peregrini prescreve o uso da agudeza. A cautela 11 trata do discurso narrativo ou histórico. Peregrini diz que se deve evitar a agudeza no gênero histórico, porque seu uso prejudica o provável, logo o verossímil. E dá o exemplo de Plutarco: se Plutarco escrevesse a vida de Alexandre com agudezas jocosas, o argumento heroico seria ridículo. Na obra histórica, é vetada como agudeza do narrador, não como agudeza da matéria narrada (diferença entre o objeto e a qualidade de sua eloquência). Deve-se evitar a agudeza em composições graves, de gênero elevado. Gêneros deliberativo e judicial: sérios. Gênero demonstrativo: sério (louvor); não sério (vituperação).

Em carta a Duarte Ribeiro de Macedo, datada de 19 de abril de 1670, D. Luís de Menezes, $4^{\mathrm{o}}$ Conde da Ericeira, comenta, autorizando-se em Mascardi, o estilo empregue por ele na escrita da História de Portugal Restaurado, em particular o uso comedido de metáforas no gênero histórico:

Tenho feito particular estudo do modo de usar delas [das metáforas], acho exemplos por uma, e outra parte muito dignos de seguir, e não encontro exemplo constante, como diz Mascardi, que possa dar lei infalível de 
sentenças, porque Tucídides foi abundante delas, Eródoto [sic], pobre, usou-as muito Salústio, Tito Lívio pouco, foi delas liberal Tácito, César escasso, e acrescenta Mascardi que o bom juízo deve usar das sentenças quando lhe caírem, mas tão bem cerzidas que pareçam como os botões de diamantes no vestido de pano, donde une a arte o que rouba a natureza. Ultimamente Mascardi não quer a história melancólica, nem a eloquência cadáver. $\mathrm{O}$ de que fujo com grande cuidado é de ideias poéticas, em que o exercício me faz tropeçar; procuro levantar conceitos da mesma tessitura, seguindo a doutrina do P. Vieira que me disse desprezar sempre os que lha não ordiam (MENEZES, 1970).

Anticiceronianos doutrinam variar os modelos. O estilo histórico deve ser brilhante, como propõe Virgilio Malvezzi no “Al Leitor” dos Sucessos Principales de la Monarquia de España ... (MALVEZZI, 1682) e o ânonimo do "Prólogo" do Seneca Impugnado de Seneca en Questiones Politicas y Morales. Brilhante é postulado erasmiano construído por meio das metáforas estilísticas de pedras preciosas e joias (SÊNECA, 1661). Anticiceronianos doutrinam, também, estilo exercitado, não medíocre, lento e de múltiplas leituras. Estilo breve, simples, claro, elegante e decoroso lipsianamente pensado. A frase não deve ser composta de longos períodos, mas curta, sem uso de conectivos, pouco ornada e sem muitas alegorias. A simplicidade, a clareza, a elegância e o decoro são critérios qualitativos homólogos entre letrados de ambos os lados do debate. Parece, no entanto, haver divergência no entendimento e no uso dessas categorias estilísticas. Anticiceronianos acrescentam à verdade, à clareza e à pureza de estilo o vigor, categoria com a qual pensam a agudeza e maravilha do estilo que preceituam como discreto, conciso, sutil, noticioso, facundo, variado conforme a matéria. A narração histórica deve ser adornada e não uma simples e "chã" narrativa, como postula Malvezzi. O estilo deve ser lacônico e político, rico de sentenças, ao contrário do que doutrinam ciceronianos repreendedores da riqueza das sentenças. Anticiceronianos definem o estilo histórico como cortesão, dotado de palavras pomposas, peregrino, singular, estranho, avesso ao medíocre e ao rasteiro. No "Ao Leitor” dos Sucesos Principales de la Monarquia de España ..., por exemplo, Malvezzi (1962) diz aproveitar-se da Arte para não escrever "História com uma simples narração somente". Vale-se de todo seu espírito para adorná-la, pois julga isso "preciso a quem dá razões ao maior Rei do mundo". Faz várias metáforas de adornos de ouro, de joias, de preciosos tecidos, de bordados, de sedas interrogando, pateticamente, o leitor se ele o condenaria por esse modo de escrever. 
Penso, com Beugnot, haver uma ruptura entre duas escolas históricas, no século XVII, para a questão do estilo. Uma asiática, defendendo o fluens dicendi genus (Agostino Mascardi do Dell'Arte Historica). Outra, ática, inspirada pelo modelo de Tácito e de Sêneca, procurando o factum dicendi genus, linguagem de soldado e de político, cujo estilo é o da ação. Esta obscura ou imperatória brevitas associada à palavra real e principesca nutrirá a reflexão moral ulterior (BEUGNOT, 1999, p. 567).

Em todo caso, o estilo seiscentista do gênero histórico não é expressão de uma subjetividade psicologizada ou mera expressividade de uma biografia empírica, mas usos de convenções de caracteres e afetos em disputas, em concorrência ou co-presença. Estilo entendido como fides, sinceridade ou fé retórica.

É possível concluir que, para além da história de longa duração dos debates sobre estilo e poder das representações, segundo apoiadores e detratores de Cícero e os modos de imitação em prosa segundo Cícero ou seus contrários, temos Polêmicas no século XVII que repõem ou atualizam o gênero diatribe, dialéxis ou controvérsia. A documentação com a qual trabalhei mostra isso, por exemplo, na batalha epistolar de acadêmicos como Mascardi, Marino, Malvezzi e Peregrini. A história de ciceronianismo/anticiceronianismo é uma diatribe também seiscentista, uma controvérsia como caracterizei e defini no início de meu texto. E com isso, no redondo ciceroniano, mas também lacunar e elíptico de Lipsio, aqui termino. 


\section{Bibliografia}

ALBUQUERQUE, Martim de. A Sombra de Maquiavel e a Ética Tradicional Portuguesa - Ensaio de História das Ideias Politicas. Lisboa: Faculdade de Letras da Universidade de Lisboa, Instituto Histórico Infante Dom Henrique, 1974.

ARISTÓTELES. Retórica. Trad. e notas de Manuel Alexandre Júnior, Paulo Farmhouse Alberto, Abel do Nascimento Pena. Intr. de Manuel Alexandre Júnior. Lisboa: Imprensa Nacional/Casa da Moeda, 1998.

BAKHTIN, M. Problemas da poética de Dostoievski. Trad. Paulo Bezerra. 4. ed. Rio de Janeiro: Forense Universitária, 2008.

BAKHTIN, M. M. (VOLOCHINOV, V. N.). Marxismo e filosofia da linguagem. Problemas fundamentais do método sociológico na ciência da linguagem. Trad. Michel Lahud; Yara Frateschi Vieira. 11 ed. São Paulo: HUCITEC, 2004.

BERGER, Klaus. As formas literárias do Novo Testamento. São Paulo: Loyola, 1998.

BEUGNOT, Benard. "La précellence du style moyen (1625-1650)". In: _ FUMAROLI, Marc. Histoire de la rhétorique dans l'Europe moderne (1450-1950). Paris: Press Universitaires de France, 1999.

BLUTEAU, Rafael. Vocabulário Português e Latino (...). Coimbra: Colégio das Artes da Companhia de Jesus, 1712.

BRAUDEL, Fernand. Escritos sobre a História. São Paulo: Perspectiva, 1978.

CÍCERO. "De Oratore". In: Obras Escolhidas. Buenos Aires: Livraria El Ateneu Editorial, s/d.

CHIAPPETTA, Angélica. "Alguns usos da escrita segundo Brutus". In: Clássica, v.13/14, 2000/2001.

FUMAROLI, Marc. L'Âge de L'Éloquence - Rhétorique et 'res literaria'de la Renaissance au seuil de l'époque classique. 2 ed. Paris: Albin Michel, 1994.

GRAZIOSI, Elisabetta. "Cesura per il Secolo dei Genovesi: Anton Giulio Brignole Sale". In: Anton Giulio Brignole Sale - Um ritratto letterario. Atti del convegno organizzato dal Dipartimento di Italianistica dell'Università di Genova com la partecipazione del Comune di Genova e dalla Galleria Nazionale di Palazzo Spinola. Genova: Palazzo Ducale/Palazzo Spinola, 11-12 aprile, 1997. A cura di Claudio Costantini, Quinto Marini e Franco Vazzoler. Quaderni di Storia e Letteratura, luglio 2000.

MALVEZZI, Virgilio. Sucesos Principales de la Monarquia de España en el año de mil seiscentos e treinta i nueve escritos por el Marques Virgilio Malvezzi del Consejo de Guerra de su Magestad; Famiano Strada, Primera Decada de las Guerras de Flandes, desde la Muerte del Emperador Carlos V. Hasta el Principio del Gobierno de Alexandro Farnese, Tercero Duque de Parma y Placencia. Escrita en 
Latim por el P. Famiano Estrada, de la Compañia de Jesus. Y Traducida en Romance, por el P. Melchior de Novar, de la Misma Compañia. Corrigida y enmendada por el Doctor de Bonnemaison. Colonia, 1682.

MASCARDI, Agostino. Dell'Arte Historica. Tratatti Cinque. Coi sommarii di tutta l'opera estratti dal Sig. Girolamo Marcucci. Roma: Apresso Giacomo Facciotti, 1636.

MENEZES, Luís de. "Carta de 19 de Abril de 1670 do Conde da Ericeira a Duarte Ribeiro de Macedo". In: RAU, Virgínia. Um 'Trabalho Divertido' do Conde da Ericeira: A História de Portugal Restaurado. Separata de Aufsätze zur portugiesischen Kulturgeschichte (10 Band 1970), pp. 304-310.

MOUCHEL, Christian. "Le rhétoriques Post-tridentines (1570-1600): La Fabrique d'une Société Chrétienne". In: FUMAROLI, Marc. Histoire de la rhétorique dans l'Europe moderne (1450-1950). Paris: Presses Universitaires de France, 1999.

PEREGRINI, Matheu. Delle acutezze (...). Genova/Bologna: Presso Clemente Ferroni, 1639.

SALLUM, Jorge. "Entre Retórica, Lógica e Dialética: Aspectos da divisio nas stasis de Hermágoras e nas declamações de Sêneca o Velho". In: Cadernos UFS Filosofia, Fasc. XIII, vol. 8, agosto a dezembro de 2010, p. 109-130.

SÊNECA. Seneca Impugnado de Seneca en Questiones Politicas y Morales. $2^{a}$ Impression Añadida con Diferentes Questiones. Por Don Alonso Nuñez de Castro, Coronista General de Su Magestad en estos Reynos. Madrid, 1661.

VIEIRA, Antônio. "Sermão da Sexagéssima". In: Antonio Vieira - Sermões. Organização de Alcir Pécora. São Paulo: Hedra, 2001.

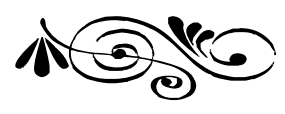

